Disabilities in academic workplaces: experiences of human and physical geographers 


\section{Disabilities in academic workplaces: experiences of human and physical geographers}

\section{Introduction}

This paper reflects upon the experiences of seventy-five university-based human and physical geographers who define themselves as disabled. We explore how diverse disabilities intersect with academic careers, lifestyles and workplaces, focusing upon some common disciplinary and institutional spaces of human and physical geography. We begin by locating the paper in two contexts. First, we contextualise the paper in relation to critiques of the limited accommodation of diverse identities and bodies within the academy. In particular, we foreground autoethnographic testimonies by scholars such as Vera Chouinard and Tanya Titchkosky, as disquieting prompts for critical reflection. Second, we situate the paper in relation to geographical research on disability, impairment and illness. Here we note a gathering apprehension of everyday sociospatial complexities of disabilities, and key points of connection to geographies and sociologies of the workplace. Pursuing these lines of thought, and following a methodological introduction, we present qualitative and quantitative data from a survey which explored experiences of disabled human and physical geographers within everyday spaces of academic workplaces.

\section{Disabilities and academic workplaces/careers}

\section{i). Accommodating and reproducing disability in the academy}

The experiences of disabled academics have often been foregrounded within a broader history of debates and struggles around the accommodation of diverse identities in an overwhelmingly masculinist, ableist, heteronormative, minority world-centric academy. Perhaps most poignantly, the autoethnographic testimonies of authors like Chouinard and Titchkosky have constituted a disquieting "beginning place" for critical research and activisms within academic disciplines, institutions and departments (Titchkosky 2008, 41). These authors' personal reflections - consider Chouinard $(1996,2011)$ on wheelchair usage, doors, salaries, workload allocation and performance evaluation, or Titchkosky (2008, Michalko and Titchkosky, 2001) on toilet location, signage, and 
dismaying encounters with colleagues, in Canadian social sciences departments - prompt four observations.

First, it is apparent that academic workplaces remain deeply, perhaps disproportionately, challenging, unpleasant and anxiety-inducing contexts for at least some disabled employees. Such accounts evoke something of the difficulties faced by disabled academic staff and the "enormous personal and professional toll of coping with struggles for accommodation" (Chouinard 2011, 162): despite decades of progress by disability rights activisms, policy shifts which explicitly require workplace accessibility, and helpful, well-intentioned work by colleagues. Indeed, second, though it is recognised that disabled identities are complexly multispatial (Crooks and Chouinard 2006), intersectional (Crooks et al., 2008) and distributed across individuals' entire lifeworlds (Dyck 1995), it is evident that the academic workplace is frequently a key site in the constitution of individuals' disablement, given the vocational significance of academic interests and status and for individuals' identity and sense of self (Chouinard and Grant 1995). Specifically, in these authors' accounts, there is a recurring sense or anticipation of disability-as-loss: of career, income, selfworth, ability or productivity (Crooks and Chouinard 2006).

Third, these accounts identify a number of silences around the constitution of ableist norms and exclusions in and through the academic workplace itself. That is, they highlight how daily “structures of normalcy" within academia (Titchkosky 2001, 133) (re)produce ableism via oftenmicrogeographical "sociospatial practices of devaluation, marginalisation and exclusion" (Chouinard 2011, 162) through, for example, glances, gestures, norms, customary practices, socialities and 'ordinary talk' in workplaces (Titchkosky 2008). In so doing, they challenge the "perverse illogic" of ableist, masculinist norms - around success, attainment, productivity, ambition, competitiveness, performance - which are implicitly inherent to many spaces of academic labour (Chouinard 2011, 162, also Thomas and Davies 2002, Allen and Imrie 2010). 
Fourth, these accounts suggest ways in which academic workplaces are part and parcel of the broader regulatory, political, legislative and discursive (re)production of disability. For example, they identify legislative shifts and policy interventions as key moments through which particular notions of disability come to be reproduced, institutionalised and enacted within sociospatial practices of the academy (Titchkosky 2007). Here it is instructive to consider critical analyses of the codification of disability in employment and human/civil rights legislation in the EU, North America and Australasia (see IDRM, 2004). To give one example, in the UK - where most participants in this research were based - the Disability Discrimination Act (HMSO 1995, 2005) and Equality Act (HMSO 2010) have formalised a particular definition of 'disability' and a particular frame of responsibilities for employers (Corker 2000). In this context, disability is legally defined as "a physical or mental impairment that has a substantial and long-term adverse effect on [one's] ability to carry out normal day-to-day activities" (HMSO 1995, section 1.1). In relation to workplaces and institutions, this statutory context constituted a particular notion of corporate responsibility, predicated upon an obligation to make "reasonable adjustments" to preclude “plac[ing] [a] disabled person... at a substantial disadvantage in comparison to persons who are not disabled" (Ibid., section 6.1). As many critics have noted, this notion of 'reasonable adjustments' can encourage an understanding of disablement as essentially fixable via modest, iterative, instrumental amendments to 'arrangements or features' of the workplace such as buildings, equipment, signage, workloads, training and supervision arrangements. Moreover - again, paraphrasing a large critical literature - this requirement for 'reasonable adjustments' typically only applies where an individual's disabilities are disclosed in the workplace because, “[n]othing in [section 6.1 cited above] imposes any duty on an employer in relation to a disabled person if the employer does not know, and could not reasonably be expected to know...that that person has a disability" (Ibid., section 6.6). While the precise form and phrasing of these discourses are peculiar to the UK, their subtext and effect - stabilising a notion of disability as requiring instrumental, 
technical or architectural fixes in response to individualised (typically medicalised) disclosures are familiar from critiques of a broader, contemporary sweep of international legislation since the 1980s (see Barnes and Mercer 2010, Vanhala 2010).

Emerging from the autoethnographic observations of fellow academics, the four observations outlined in this section have (after Titchkosky 2008) afforded a disquieting beginning place for our research. In the project reported in this paper we sought to explore concurrences and differences in experiences of diversely disabled academic staff, at different career stages, in different kinds of institutions, and operating in diverse geographical subdisciplines. Our project also emerged from what we take to be an imbalance in responses of the UK higher education sector - and our specific disciplinary home of human geography - to the statutory context outlined in the preceding paragraph. For, looking at the substantial body of sector-wide and discipline-specific research and guidance dealing with disabilities in higher education (DRC 2007; EHRC 2010; QAA 2000, 2010), we note a strong focus upon the needs and experiences of diverse disabled students. For example, there is a substantial literature exploring the needs of disabled students who are geographers or earth/environmental scientists. As a tutor in one of these disciplines, one can readily locate detailed, evidence-based guidance on supporting students with impaired mobility (Gardiner and Anwar 2001), vision (Shepherd 2001) or hearing (Wareham et al. 2001), mental health conditions (Birnie and Grant 2001), learning disabilities (Chalkley and Waterfield 2001), and other conditions (Healey et al. 2001). However, in marked contrast, sector-wide and discipline-specific guidelines are typically characterised by much more limited consideration of experiences of disabled staff engaged in teaching and research within higher education. Certainly, as yet, there is no comparable, parallel body of research and guidance with which to understand and support the needs of disabled people in the contexts of academic careers, institutions and disciplines (see ECU 2004, NIACE 2008). 


\section{ii). Geographies of disability, impairment and illness}

A significant body of geographical research focusing upon disability, impairment and ill-health has also emerged during the last two decades (see Park et al. 1998; Imrie and Edwards 2007; Chouinard et al. 2010). Three key contributions of this geographical research have been as follows. First, most simply, geographers have conducted numerous, new, in-depth studies, in a social-historical context where "perspectives and experiences of disabled people in their own words...remain vastly unreported" (Hansen and Philo 2007, 499). Geographers have advocated and developed qualitative and auto/ethnographic research to explore "the embodied reality of disability in everyday life..., how the people concerned 'notice' their impaired bodies when seeking to go about their daily business (going to work, attending classes, using shops, cinemas or parks, taking a child to the swings)...[and] the embodied 'art' of managing the time, space and speed realities of 'doing' daily living" (Ibid., 497). In so doing, the geographies of an increasingly diverse range of disabilities, impairments and illnesses have been mapped.

Second, moreover, geographers have foregrounded an increasingly diverse range of spaces of disability, impairment and illness. Here, geographical research has characteristically gone "beyond medical spaces and relations" (Parr 2008, 27) - that is, beyond a narrow focus on spaces normatively associated with, or 'reserved' for, 'ill-health' - to explore experiences of disabilities in multiple everyday spaces. Geographers have thus highlighted some often-overlooked experiences of - and, importantly, possibilities for - disabled people's lives. Parr's (2008, ix) work on mental health is especially important here, as she challenges prevailing popular, political and medical discourses which overwhelmingly figure 'the mental patient' as a hope-less figure of "essential difference and stigma" (p.ix), in need of (medicalised) treatment. To disrupt these limited, static, exclusionary representations, Parr directs attention towards more 'hopeful' experiences and spaces: for example, towards sites of care, support and solidarity, and practices through which "people with mental health conditions are active in rescripting their own social recoveries from a stigmatized and 
static figuring of "mental health patient"' (p.x). In a similar vein, a number of geographers have begin to explore 'hopeful' spaces of care, rest, respite, support, recovery, survival, coping and radicalisation in relation to diverse disabilities and chronic illnesses (Conradson 2003; Parr 2003).

Third, in so doing, geographers have begun to articulate the importance of spatial processes in the ongoing constitution of disabilities, illnesses and impairments (Curtis 2010). Geographers' work reveals how experiences, identities and emotions/affects associated with disability and illness are complexly distributed through bodies, spaces, materials, situations and lifecourses (Worth 2009). In Parr's $(2008, x)$ research, for example, the experiences and identities of people with mental health conditions are inextricably linked to the complex, interconnected microgeographies of "parks, pubs, streets, hostels, residential placements, drop-ins, homes, projects, offices, art studios, gardens and internet chatrooms, to name just a few... locations”. Moreover, geographers have begun to articulate the multiscalar social, political and historical processes which pattern experiences of disabilities: complex "geographies which range from the global to the nation state to the living room to the body to the imagination" (Parr and Butler 1999, 6), which are constituted by "dynamic and ongoing interactions... between minds/bodies and specific cultural/social configurations" via materialities, and formal, normative and/or cultural politics (Chouinard et al. 2010, 6; Hahn 1986, Holt 2007). This attentiveness to complex spatial processes has led geographers to eschew neat, normative static binaries like 'disabled'/'ablebodied' and 'social model'/'medical model' in favour of more careful and complex, processual understandings (Butler and Bowlby 1997, Holt 2007, Worth 2008).

The workplace has often been a specific focus for social scientists exploring the instanciation of disablement and ableism in particular spaces (Moss and Dyck 2002). Broader geographical and sociological studies of workplaces have been an important influence here, in their critique of abstract, uncritical notions of 'the workplace' (or 'the city', 'the economy', or - as in this paper - 
'the department', 'the institution', 'the discipline'), and their recognition that workplaces are "only too real - places in which real people [live] and...work" (McDowell 1997, 3). This analytic lens has enabled geographers studying disability, impairment and ill-health to extend longstanding social scientific and policy-oriented research on disability and the labour market (DWP 2004), by exploring intersections between disabilities and the everyday sociospatial practices, conventions and micropolitics of workplaces (Dyck 1999; Hall 1999; Crooks 2008). Such studies reveal the extent to which socio-material workplace geographies can constitute barriers, challenges and frustrations for disabled employees: often mitigating against hope-ful geographies and reproducing profound disadvantages, exclusions and accommodation struggles. Work in this context has ranged across diverse employment contexts. However, as Chouinard (1997, 1999), Moss (1999) and Worth (2008) note in their qualitative or autoethnographic work, research on disabilities in academic workplaces and careers remains relatively underdeveloped. In the project described in this paper, we sought to collate accounts of diverse disabled human and physical geographers, to explore how disabilities intersect with everyday workplace geographies of disciplinary geography. While some of the following findings may be particular to this disciplinary context - perhaps framed by the peculiar normative, expeditionary masculinisms which continue to have currency in geographical workplaces (McDowell 1990, Rose 1993) - we suggest that our findings should also raise questions about academic workplaces in other disciplinary contexts.

\footnotetext{
About the project

In these contexts, our project used an online survey to record some experiences of disabled staff engaged in university-based research or teaching in human or physical geography. Despite initial misgivings about this method (being social/cultural geographers committed to qualitative and ethnographic methods) an online survey provided a solution to two key challenges: (i) a desire to consult with as broad and diverse a sample as possible; (ii) the need to guarantee respondents' anonymity, affording them space to discuss sensitive personal experiences which they may not
} 
otherwise disclose. The online survey included qualitative and quantitative questions about: the nature of individuals' disabilities; disclosure of disabilities within workplaces; experiences of disabilities within disciplines, institutions and departments; recommendations for change and action in these spaces. The survey was publicised via Anglophone mailing lists, websites, networks and conferences for human and physical geographers and earth/environmental scientists. We called for respondents who considered themselves 'disabled' as defined by in the UK policy context, judging this to be a pragmatic point of departure, despite our commitment to the critiques already outlined ${ }^{1}$. Our call for respondents attempted to accommodate a wide range of potential participants encompassed by this definition ${ }^{2}$ :

We are conducting research exploring experiences of academics and researchers with "a physical or mental [condition] that has a substantial and long-term... effect on... day-to-day activities" (HMSO 1995, section 1.1)... This might include: long-term illness; mobility difficulties; sensory impairments; mental health problems; compulsive behaviours; alcohol/substance misuse; dyslexia; learning/communication difficulties; debilitating injuries; chronic pain; autistic spectrum conditions; 'hidden' disabilities.

Seventy-five people completed the survey. Characteristics of these respondents are summarised in table I: they encompassed diverse disabilities, roles, institutions, disciplinary backgrounds, and career stages. However, these respondents should not be understood as representative of all Geographers with disabilities $^{3}$ : for, as we outline in the following section, two particular, selfselecting groups of respondents tended to complete the survey.

[Table I about here]

\footnotetext{
${ }^{1}$ We want to make our position quite clear here, and own up to an anxiety. As suggested in the preceding sections, we are committed to: (i) critiques - principally derived from social models of disability - of the social, normative and discursive construction of 'disability'; (ii) conceptualisations - such as those emerging from geographical work on health, well-being and embodiment - which accommodate the complex bodily conditions and social geographies which constitute disablement in practice. Our anxiety is that, despite these political, critical and conceptual coordinates, it still felt pragmatic, useful and necessary to use the Disability Discrimination Act definition as point of departure when publicising our research. Our initial sense that we needed a neat, a priori definition of 'disability' when launching our survey - and our falling back on a widely-circulated language when communicating with potential participants - does not mean that we champion the problematically medicalised, functionalist logics of the definition (although it does, admittedly, suggest just how intractable those logics can be).

2 The call for responses also indicated that the survey was available in alternative formats as required by individual participants.

${ }^{3}$ Indeed, some conditions listed in our call for respondents were not represented in responses. In particular, we received no responses from geographers with dyslexia, autistic spectrum conditions, or diverse cognitive or behavioural conditions. This may be because: (i) potential respondents did not feel that these conditions had a 'substantial and long-term effect'; (ii) despite our efforts, the medium of the survey, or the call for respondents, was not inclusive for those with these conditions; (iii) people with these conditions are genuinely underrepresented within academia. Further research is required to understand the issues and needs of those with diverse 'hidden disabilities' working in academic workplaces (Price 2011).
} 
Contrary to our initial hesitancy about the efficacy of an online survey (see also Worth 2008), many respondents used the confidential frame of the survey to write long, often deeply affecting ${ }^{4}$, accounts of their experiences. In the remainder of this paper we explore the different kinds of responses we received. We begin with an overview of responses, identifying commonalities but also two contrasting groups of respondents therein. We then discuss the experiences of each of these groups in turn, in relation to some specific spaces and practices of academic workplaces and careers. In conclusion, we present respondents' recommendations for change within everyday spaces of their academic departments, institutions and disciplines.

\section{Overview of responses: disclosed and undisclosed conditions}

Before discussing different groups of responses to the survey, it is important to note some commonalities shared by respondents. All respondents reported forms and degrees of accommodation struggle and exclusionary spatial processes within their workplaces. Most respondents reported that their disability had had an adverse effect on their research (60/75), teaching (51/75) and career development (67/75). In this paper, we highlight diversities within this overall picture. Broadly, we received two groups of responses to the online survey, principally differentiated by the extent to which individuals disclosed their disability in their workplace. On one hand, some respondents recalled how the experience or onset of disability had sparked impassioned, politicised work to transform academic practices, workplaces, institutions or disciplines. On the other hand, however, some respondents used the confidential space of the survey

\footnotetext{
${ }^{4}$ The online survey concluded with a list of contact details for support services/networks, should respondents have felt the need to seek
} advice or support in relation to issues discussed in the survey. 
to report conditions, experiences and issues which they had not disclosed within their workplace. As an indicator of disability disclosure, the online survey asked respondents to indicate whether they had disclosed their condition to different people in their workplace. Responses are summarised in table II, and were sharply polarised: between respondents (36/75) who had disclosed their condition to all of the listed individuals versus those $(31 / 75)$ who had disclosed their condition to 'no-one' within their workplace.

[Table II about here]

Clearly, extent of disclosure was closely related to type of condition: all respondents who had disclosed their condition to 'no-one' had some form of mental health condition ${ }^{5}$. This finding is perhaps unsurprising, given extant research highlighting how mental health conditions are frequently stigmatised and 'hidden' (Brunner 2007; Irvine 2009). For example, many recent studies of disabilities in workplaces have described how "widespread unease and anxiety about disclosing other-than-obvious impairments", leads some employees with mental health conditions to adopt tactics of 'nondisclosure' or 'delayed disclosure' to 'keep up appearances' and 'make a good impression' (NIACE 2008, 9; RCPsych 2008). Certainly, in our study, many ( $\mathrm{n}=15)$ respondents who disclosed their condition to 'no-one' in the workplace explicitly explained their non-disclosure as a strategic response to a stigmatisation of mental health conditions - as 'weakness' (see Sainsbury et al. 2008) - within their disciplines, institutions and departments.

"I haven't... disclosed my condition to people - partly because of stigma... also the competitive atmosphere in the university and present conditions make it seem like a weakness" (Human geographer, mental health condition)

"Mental illness still carries a negative stigma in the workplace, especially in a 'competitive' environment like academia. For that reason I have not disclosed my condition to anyone in the department and have successfully hidden it from colleagues despite having episodes that have resulted in disabling conditions on several occasions. I have attributed these disabling mental episodes to physical conditions that evoke more sympathy in my colleagues" (Physical geographer, mental health condition)

\footnotetext{
${ }^{5}$ Most of these respondents suffered from common forms of depression which had not prevented them from continuing in full-time employment. Harvey et al. (2009) and Irvine (2009) note that the experiences of such individuals are often underrepresented in clinical and social scientific research on mental health, which has tended to foreground more 'severe', debilitating forms of mental illness.
} 
However, we suggest that the divergent responses prompted by the survey should not be understood solely in terms of a categorical difference between ('hideable') mental health conditions and other ('visiable') disabilities: note, in table II, that around one-fifth (10/48) of those with mental health conditions had disclosed their condition to most colleagues and students. The nature and seniority of respondents' job roles was evidently important here. As table III suggests, most (12/17) respondents who had disclosed mental health conditions in the workplace were relatively established lecturers, senior lecturers or professors. These respondents typically linked the disclosure of their condition to their status and experience within their workplace. As in previous accounts of disabilities in workplaces (see Dyck 1999; Sainsbury et al. 2008) this seniority evidently afforded job security, practical coping strategies, collegiate networks of support, understanding of systems, and 'clout' to effect change. Most of these respondents had longstanding mental health conditions, but only disclosed them once they had developed 'clout', know-how and coping strategies.

"[Disclosure is] easier when you have some 'clout' and know how things work" (Human geographer, mental health condition)

"After 7 years I can just about cope [with] 'juggling' depression and teaching. Over time I have learnt little tricks that make it less stressful... Also easier to disclose [mental health conditions] when you are more established" (Physical geographer, mental health condition)

[Table III about here]

By contrast, most (23/31) of those who reported undisclosed mental health conditions were early career lecturers, research assistants or teaching assistants. These respondents frequently articulated their nondisclosure in terms of their insecurity, 'insignificance' and 'replace-ability' within their departments and/or institutions (see also Ní Laoire and Shelton 2003) ${ }^{6}$.

\footnotetext{
${ }^{6}$ We note that many of the anxieties relayed by respondents in this paper - job security, fixed term contracts, self-presentation - will undoubtedly intersect with gendered inequalities in workplaces (see Moss and Dyck 2002). However, the small proportion of respondents who disclosed their gender in our survey precludes definitive analysis.
} 
"I feel my depression is insignificant... I'm just one small, replaceable part of the department" (Human geographer, mental health condition)

My department doesn't feel that individual problems should affect the overall running... 'If you can't take the heat, get out of the kitchen' seems to be the message" (Physical geographer, mental health condition)

In summary, then, our survey received two sets of responses: (i) accounts from relatively established human and physical geographers who had been active and politicised in relation to their diverse disabilities; (ii) accounts by relatively young geographers with mental health conditions which are undisclosed in workplace contexts. Clearly, these self-selecting groups must not be read as representing all 'geographers with disabilities': rather, the accounts reported in this paper should be understood as two self-selecting, and perhaps extreme, clusters on a spectrum of experiences.

The remainder of this paper will consider the experiences of each of these groups in turn. Following Parr's lead, we begin by foregrounding the 'hopeful' practices of the former group, particularly their work to effect change in relation to multiple aspects of institutional and disciplinary spaces. However, we then recognise that these 'hopeful' practices do not seem possible - not always, not everywhere, not yet - for all disabled geographers, through a discussion of the experiences of geographers with undisclosed mental health conditions.

\section{Activist dispositions: delivering a 'kick up the backside'}

"I have become quite 'bolshy' as a result of my condition" (Physical geographer, mobility impairment)

"A lot of departments need a kick up the backside - they are behind the times!" (Physical geographer, sensory impairment)

For some respondents - typically those with sensory or mobility impairments - the experience or onset of disability had sparked somewhat activist dispositions: feelings of anger or (self-confessed) 'bolshy'-ness about academic and disciplinary norms, or a desire to give their department a 'kick up the backside'. These respondents typically recalled how this disposition gradually developed from 
initial, individual, incremental negotiations about modifying the workplace (or what would be termed 'reasonable adjustments' in the UK). Most described a shift from 'trying to continue as before' (or 'as normal') to 'rethinking how things are done'.

"When I arrived the department was in the stone age as far as accessibility is concerned - but the department has been very willing and made constant incremental changes to accommodate me (this weeks challenge $=$ reviewing institutional evacuation procedures!). After nearly 10 years, we are getting there!" (Human geographer, sensory impairment)

"I have gone from stubbornly trying to continue as before (and getting frustrated when this proved impossible) to rethinking how I do things" (Physical geographer, mobility impairment)

These respondents described how initially-individualised experiences and negotiations prompted them to be become more widely concerned with the able-ism of their departments, institutions and disciplines. Specifically, they tended to undertake activities in five related areas. While keen to celebrate these hope-ful practices, in the following summary we are also mindful of aforementioned critiques of policy, institutional and workplace responses to disabilities. We note that the following points largely relate to specific, post-hoc technical, tangible, visible, solveable adjustments and amendments, which typically represent only tentative steps towards anything like a fundamental rethink of the institutional and disciplinary norms which make these amendments necessary (Michalko and Titchkosky 2001, Chouinard 2011). We also note something of a cycle here, whereby (often established) staff with disclosed (typically 'visible') conditions are seen to attain tangible accommodation successes (Chouinard and Grant 1995): and we will go on to contrast this situation with the experiences of disabled academics who feel unable or unwilling to disclose more 'hidden', stigmatised conditions which are less 'readily' (after Crooks 2007) supported within institutional spaces.

So, first, some respondents $(\mathrm{n}=13)$ had protested about, and often prompted significant adjustments to, the built environment of their department, campus or institution. These adjustments related both to their own needs and - subsequently - to the needs of other colleagues and students. In the 
process, these respondents had evidently become spokespeople for diverse on-campus accessibility issues: 'taking forward other people's issues', 'leading...general rethinking about inclusion'.

"Have complained about all kinds of campus accessibility issues - not just relating to me, but have taken forward other people's issues too" (Physical geographer, mobility impairment)

"Had to work hard to get... changes to make classroom spaces more accessible to me (and a range of other 'handicaps')... [leading to] general rethinking at departmental level about why we do certain things in a certain way and generally more discussion about inclusion" (Physical geographer, mobility impairment)

Second, some respondents $(\mathrm{n}=14)$ had prompted significant adjustments to both the content and delivery of taught courses at their institution. These adjustments typically comprised two levels: incorporating studies of disability, accessibility or broader issues of embodiment, emotions and social exclusion into curricula; and, more broadly, fostering the development of more inclusive teaching/learning practices.

"Teaching specialisms relating to [disability] and body...[also] active in developing our department's provision for mental health concerns - making sure people know how to deal sensitively when issues arise" (Human geographer, mental health condition)

"I have led discussions on replacing lecture blocks with shorter learning activities...My condition has prompted me to take an active interest in developing inclusive curricula and teaching practices" (Physical geographer, long-term illness)

Third, some respondents $(\mathrm{n}=13)$ had been specifically active in reconfiguring residential fieldtrips offered by geography departments. Again, they had incorporated disability and accessibility topics into existing fieldtrips and, more fundamentally, sought to enhance accessibility of field practices in human and physical geography. For most, this process entailed some degree of critical reflection upon enduring, ableist norms of expeditionary fieldwork.

"Inability to climb to a favourite viewpoint [as a result of onset of condition]. Now use the path to think about the inaccessibility of certain field experiences" (Physical geographer, mobility impairment)

"My involvement has helped the team to reflect on where we go and what we do. Some activities that have taken place in locations in the past have been changed - e.g. long walks around a city centre, hikes across rough ground. The team has agreed that everyone should be able to participate fully - staff and students - and activities have been altered to ensure that this is the case" (Human geographer, mobility impairment) 
Fourth, several respondents $(n=7)$ had been active in developing formal and informal support networks for disabled staff and students within their institution. Other respondents had been instrumental in developing institutional disability equality training programmes. These were areas in which respondents with disclosed mental health conditions were especially active.

"I run a peer support group with a few other people in my dept - we have done events to raise awareness of mental health issues in Higher Education" (Physical geographer, mental health condition)

"Have been able to intervene when I've noticed students with difficult relationships to food... Work with colleagues to offer (confidential) advice to staff and students with mental health problems" (Human geographer, mental health condition)

Fifth, several respondents $(n=8)$ described how their experiences had led them to undertake diverse action research projects relating to specific disabilities and illnesses. Others had led pedagogic research projects about accessibility in teaching/learning contexts.

"Undertaken projects on mobility/access difficulties as direct result of my experiences" (Human geographer, mobility impairment)

"Research on embodiment, [name of condition] - my research is like the one area of my life where I can deal with these complex issues" (Human geographer, mental health condition)

For these geographers, as for participants in Worth's $(2008,307)$ research, the 'personal reckoning' of disability had been productive in "making the personal political, using the emotions and experience of disability to create critical research". Other respondents (notably those with disclosed mental health conditions) described more 'oblique' relationships between their conditions and research practices. Here, research was valued precisely as a means of 'reckoning' one's condition: 'reflecting on feelings', 'channelling' experiences, 'coming to terms with things'.

"I suppose the self awareness and anxiety that comes with depression is something that I...channel into scholarly practices" (Human geographer, mental health condition)

"Research offers a way of getting to grips with who I am, and the state I'm in. I never deliberately research 'about' mental health, but [research] is a way of coming to terms with things, even obliquely" (Human geographer, mental health condition) 
The respondents quoted in this section had effected some degree of affirmative change for themselves and others in each of these five areas. As a result of these contributions, several had become leading figures in institutional work on accessibility, inclusion and widening participation. Indeed, several $(n=7)$ respondents described how the 'reckoning' of disability - via the practices outlined above - had contributed directly to career development and promotions.

"My...action research in this area...contributed positively to my last promotion" (Physical geographer, sensory impairment)

"Work...on accessibility and our curricula has helped me make a 'contribution'. This may result in promotion in the next academic year" (Physical geographer, mobility impairment)

In Parr's (2008) terms, we might understand these individuals as having been able to develop 'disclosive identities' through - and resulting in - the kinds of 'hopeful', constructive work detailed in this section: even though many advances made by these respondents could be interpreted as modest, partial, post-hoc, "hollow and qualified" (see Chouinard 2011); and even though the institutional and disciplinary lives of these respondents evidently remain an ongoing, daunting challenge (Moss et al. 1999) . Certainly, the preceding quotations recall Parr's account of practices and dispositions through which disability can be re-placed and reframed, affording "multiple disclosures of the skills, abilities, strategies, tactics, personalities and achievements of the people who participate" $(2008,27)$ : However, in the following section, we consider a contrasting group of geographers with disabilities for whom such 'hopeful' practices do not seem possible.

\section{Enclosed identities: 'keeping to myself'}

“I cope with things by keeping to myself” (Physical geographer, mental health condition)

"I keep my problem to myself - this makes me feel isolated, but it is how I cope with my condition" (Earth Scientist, mental health condition)

The data presented in the preceding section contrast starkly with the experiences of many respondents with mental health conditions. These respondents shared a sense of the impossibility or, at least, ill-advisedness - of disclosing their condition within the social and organisational 
culture of their workplace (see LLUK 2009). As previously noted, they typically anticipated that their condition - and requests for adjustments to accommodate their needs - would be stigmatised as 'weakness' within their discipline and institution, and would therefore jeopardise their job security, status and identity. Moreover, some respondents described common experiences and symptoms of mental health conditions as ill-conducive to the kinds of 'disclosive' practices outlined in the previous section.

"As a result of depression...I suffer from apathy, anxiety, lack of motivation and lack of confidence in my capabilities...[This has] held me back in my career" (Human geographer, mental health condition)

"Anxiety attacks, social awkwardness...- naturally, this makes it difficult to make a contribution" (Human geographer, mental health condition)

We may query this sense of inevitability, 'nature' and resignation, particularly given the accounts of those geographers with mental health conditions quoted in the preceding section. However, in practice, many respondents with mental health conditions had adopted workplace identities which might - in contrast to Parr's (2008) disclosivity - be termed 'enclosive': resigned to 'keeping to themselves', seeking isolation and foreclosing the possibility of disclosing their condition, let alone attaining accommodatory adjustments. This feeling, prerogative and tactic of enclosure - essentially a strategy of bodily and emotional management (see Hansen and Philo 2007) - recurred in respondents' accounts of five key, commonplace sites of academic life. Notably, these were spaces where particular performative capacities of self-confidence, productivity, stamina, ambition and charisma were anticipated and valorised: through the following points we recall critiques of masculinist and ableist norms in academia (McDowell 1990, Chouinard and Grant 1995, Thomas and Davies 2002) and the peculiar, heightened manifestation of those norms in many spaces of disciplinary geography (Rose 1993).

First, some respondents $(\mathrm{n}=11)$ identified job interview and promotion panels as profoundly stressful, precisely because of a requirement to demonstrate 'disclosive', self-assured performative 
skills in these contexts. Recollections of interviews were marked by disappointment and distress:

the inevitability of 'holding back', 'letting myself down', 'not doing myself justice'.

"Have completely made a mess of several big job interviews - got shortlisted but just couldn't cope with it on the day - almost like a bodily reaction to the experience... Always hold myself back" (Human geographer, mental health condition)

"Always let myself down at interview - ...can't imagine doing myself justice" (Physical geographer, mental health condition)

Moreover, for some respondents, job applications and interviews had been significant moments in their decision not to disclose their condition in the context of their career. Occasionally, this decision was a response to first-hand experience; more commonly, however, it was based upon an anticipated need to 'keep up appearances' and perform a perceived norm. Responses such as these recall Titchkosky's (2001) discussion of 'passing', wherein efforts by individuals with hidden disabilities to 'pass' as 'normal' reveal powerful norms and anxieties which structure normalcy but overwhelmingly remain unsaid. Thus, the decision that 'it is better to keep up appearances' (cf McDowell 1990 on 'knowing one's place') directs attention to a raft of norms, expectations, fears and politics which implicitly structure academic workplaces and careers as well as the job interviews through which they are accessed.

"When I disclosed my health problems to a prospective employer, I was asked to attend a medical because of it following an interview. I wasn't offered the job after it. I expect my health didn't have anything to do with this, but it put me off disclosing my condition because the whole process was embarrassing and I've always wondered whether maybe I didn't get the job because of my health. Now I don't disclose any health problems when applying for jobs" (Human geographer, mental health condition)

"Have not disclosed my condition in interviews - believe... it is better to keep up appearances....as (especially in the current job market) I severely doubt I will be able to persuade a panel to offer me a lectureship" (Physical geographer, mental health condition)

Second, most respondents $(n=20)$ with undisclosed mental health conditions described teaching undergraduate classes as profoundly challenging: even an 'ordeal'. For these respondents, lecture 
theatres, seminar rooms and tutorial venues ${ }^{7}$ were experienced as spaces of dread, anxiety, exhaustion and disappointment.

"I find teaching an ordeal. It can affect me deeply" (Human geographer, mental health condition)

"Teaching is the most challenging thing I have ever done in my life. At times I have found it impossible to cope. I have found that... anxiety about the next class or tutorial...has profoundly affected my ability to teach. In theory, I am passionate about teaching but in practice I dread actually standing up to give a class" (Human geographer, mental health condition)

For these respondents - indeed, for most respondents with mental health conditions in our study teaching was principally described in terms of 'coping': managing one's emotional state in a space of heightened anxiety. It was recognised that such 'coping' may not commensurate with effective teaching/learning. Indeed, respondents' anxiety in teaching spaces was often compounded by their disappointment at having to compromise 'students' best interests' in order to 'keep sane'.

"During low periods, I'm afraid the quality of teaching suffers - I'm aware of this, but sometimes it is a struggle for me just to make it through a class. It is intensely frustrating- I want to do my best, but I can't help but let myself and my students down" (Physical geographer, mental health condition)

"Teaching (and the preparation, admin, marking that goes with it) is stressful for me. I have to moderate my teaching practice to reduce face-to-face contact or prolonged exposure to students. Realise that this is not in students' best interests, but I have to keep myself sane!" (Physical geographer, mental health condition)

Third, similarly, some respondents $(\mathrm{n}=13)$ described academic conferences and seminars as sites of dread and disappointment. Here, anxieties attached to public speaking and lecture theatres were compounded by the apparent confidence, excellence and 'easy' normality of peers. Some respondents worked to 'fit in' in these contexts, whereas others limited their involvement with peers or avoided conferences altogether. Each of these tactics reportedly left respondents feeling pained, exhausted and unfulfilled.

"Very low self-esteem means I am terrible at 'networking'...I am, and always will be, a defeatist. This is not helpful when one is applying for tenure or trying to impress at a conference!...Others seem to find it so easy" (Human geographer, mental health condition)

\footnotetext{
${ }^{7}$ As an extension of this discussion of the 'ordeal' of teaching, most respondents described the challenges posed by residential fieldtrips and offsite activities. We will focus upon this aspect of the experiences of disabled geographers in a forthcoming paper.
} 
"I am terrible at 'selling myself' at conferences, seminars, promotion committees etc.... Try to fit in but... have had bad experiences - the aggressive 'grilling' and 'posturing' can affect me for a long period afterwards" (Environmental Scientist, mental health condition)

Fourth, some respondents $(\mathrm{n}=12)$ experienced formal workplace meetings as difficult. Meetings of different kinds (including one-to-one meetings, discussion groups, departmental meetings, research team meetings) were cause for considerable anxiety. Respondents reported nervousness, speechlessness, distress, inadequacy - and a disappointed sense of their inevitable inability to 'make a contribution' - occasioned by these events. Again, these anxieties came to be attached to specific spaces within the workplace.

"Staff meetings are very hard - as I feel under pressure. Find I can't make a contribution. Heart sinks whenever I go to meeting room" (Physical geographer, mental health condition)

"[Research project] team meetings result in anxiety, before, during and after...Tutorials are difficult... and other contexts where I am expected to 'perform' to small groups, especially peers" (Human geographer, mental health condition)

Fifth, several respondents $(n=8)$ described their discomfort and sadness in everyday social spaces and interactions within their department. Events like coffee breaks, parties or pub visits were described as traumatic: and as Chouinard (2011) notes, feelings of exclusion from such, relatively fleeting social events can be significant in indicating and constituting exclusions from/within the academic workplace more broadly. More fleeting and regular forms of workplace sociability, like encounters in the staff corridor, were also experienced as difficult. Consequently, several respondents felt intimidated, lonely and basically unhappy within their workplace.

"Academic departments can feel like very lonely places...Often the obligation to socialise with colleagues adds to stress levels!" (Physical geographer, mental health condition)

"Social interactions are sometimes very difficult. I avoid social contact...I find situations like lunchbreaks difficult to handle... [and] going for coffee or 'good old' trips to the pub" (Human geographer, mental health condition)

"Dark nights on the staff corridor, alone in the building, writing lectures; that's when I'm at my worst" (Human geographer, mental health condition)

In relation to each of these spaces, respondents articulated a kind of 'vicious circle': academic workplaces were identified as unconducive to 'positive mental health', but the attainment of support 
or adjustments in the workplace was seen as impossible or ill-advised by many staff with mental health conditions. For, on one hand, respondents identified a range of intersecting norms, trends, pressures and habits of contemporary academic lifestyles which impacted negatively upon their mental health. For example, they noted that academic workplaces are frequently characterised by: isolated, individualised working practices; intense workloads and time pressures; long hours and the elision of barriers between work and home; anxieties around job security and contracts (particularly for early career staff); and processes of promotion and performance review which effectively valorise individual productivity, and reward and institutionalise each of the above-listed characteristics (McDowell 1990, Chouinard and Grant 1995). These characteristics - and the interactions, habits, 'codes', 'rules' and bodily practices they normalise (see Hall 1999) - surely also stall or foreclose the 'hopeful', 'disclosive' practices outlined in the previous section.

“At times, academic life makes me **physically** unwell. The prospect of going in to work, or giving a class, or making a conference presentation. Stress exacerbates mental health issues - it is a vicious circle" (Human geographer, mental health condition)

"At my institution, there are rumours of redundancies, and many teach long hours on fixed term contracts. This is not conducive to positive mental health!!!!!" (Environmental Scientist, mental health condition)

On the other hand, as previously identified, many respondents felt unwilling or unable to disclose their condition within their workplace. As in previous studies of 'hidden' disabilities in workplaces, these respondents opted to 'keep up appearances' and 'fit in', rather than revealing themselves as 'other' (cf Crooks et al. 2008 on 'acquiescence'). Dyck (1999) outlines the heightened importance of this 'fitting in' for individuals whose sense of self is closely entangled with their workplace identity: and we note that academic careers are frequently characterised by intimate entanglements of this kind, whereby individuals identify with, and commit to, 'all-consuming' research interests. Moreover, some respondents emphasised the importance of 'keeping up appearances' given the particular social and normative context of their academic discipline and department. They did not report instances of discrimination against, or disparagement of, people with mental health conditions. Rather, they often described the constant challenge of 'living up' to a set of 
expectations relating to 'being an academic'. Specifically, these expectations valorised particular performative aspects of academic practice: for example, confident public speaking, quick-witted scholarly discussions, 'charisma', 'go-getting' personality. Several respondents posited a figure of an ideal, 'superhuman' geographer. They found themselves lacking compared to their colleagues who seemed to possess 'superhuman' traits as a matter of course. In this respect, the discipline of geography was figured as not just ableist but super-ableist (see also Worth (2008) on 'hyperability').

"I am resigned to my condition holding me back in future. There seems to be an expectation that academics need to be superhuman and untouchable - anything out-of-the-ordinary is seen as a weakness" (Human geographer, mental health condition)

"There is a limit to how much I can do in a day and my endurance for writing is far lower than my peers who seem to be superhuman!" (Human geographer, mental health condition)

Respondents' accounts of this 'vicious circle' were shot through with a kind of rueful, disappointed self-awareness. At the intersection of all this - stressful working conditions, anxieties about job security, 'super'-ability as the norm, the impossibility of disclosure, disappointment at 'failure' to 'succeed' - some individuals $(\mathrm{n}=13)$ explicitly foresaw no future for themselves within their discipline.

"I cannot imagine ever succeeding at this game. I am such a bag of nerves and anxieties!" (Physical geographer, mental health condition)

"Not sure I am cut out for this career. Plan to leave ASAP. Academia messes with your head! I'm not being flippant - I really think there are a series of pressures and strains which are conducive to poor mental health. It is practically the norm to be sleep-deprived, working til the early hours, behind with deadlines, underpaid, on short contracts, full of caffeine and alcohol" (Physical geographer, mental health condition)

However, lest we fall back on figurings of mental health conditions as static and hope-less, we conclude this section by emphasising the ongoing task of coping with mental health conditions in academic workplaces. Despite the interlinked, profoundly discomforting, challenges described above, most respondents were, at least, able to 'get on with it, take each day as it comes', with a world-weary sense of 'but hey :)'. 
"[Being a geographer with a disability] is a case of some good days, some low days...You learn to get on with it, take each day as it comes" (Human Geographer, mental health condition)

"My ability to function as a researcher is limited by my condition. At the same time, my academic lifestyle makes the condition worse. But hey :) " (Human Geographer, mental health condition)

\section{Conclusion: respondents' recommendations}

In this paper, we have contributed to extant accounts on ableism in academic workplaces by highlighting concurrences and differences in the experiences of diversely disabled academic staff, at different career stages, in different kinds of institutions, and operating in diverse geographical subdisciplines. Our findings are troubling. These data suggest that disciplinary geography remains an exclusionary, unhappy place for many disabled academics, and that ableist norms and performative expectations remain inherent to many everyday spaces of academic workplaces: even in the wake of the significant disciplinary and political changes suggested in this paper's introduction. We have sought to contribute to understandings of this workplace ableism by recognising some taken-for-granted, habitual microgeographical exclusionary practices of disciplinary, institutional and departmental life. Participants' discussion of their workplace geographies suggest a number of concerns for future research: for example, to explore the experiences and needs of disabled practitioners in diverse educational spaces, roles or disciplinary contexts, or to better understand the implications of intersecting neoliberalising trends and strategies (not least towards managerialism, performance monitoring rationalisation, and commercialisation) for the constitution of disablement in higher educational contexts.

Although diverse, the day-to-day experiences of all respondents who completed our survey were beset by disappointments, frustrations, challenges and distress. These experiences are familiar from previous studies of disabilities in workplaces (Hall 1999, DWP 2004), although our data suggest how experiences are particularly patterned and compounded by norms, sites and situations of 
academic, and particularly geographical, workplaces. These data should give us pause to reflect upon the institutional and disciplinary spaces we inhabit: perhaps especially how (to quote one respondent) academic spaces may be 'conducive to poor mental health'.

As prompts for this reflection, and in the spirit of Parr's (2008) hopefulness, we conclude with respondents' recommendations for changes that could be made to departments, institutions and disciplines to improve the experiences of people with their condition. Three key recommendations were made. First, many respondents called for a change in emphasis in the way in which academic institutions approach disability: they advocated moving away from a model in which individual disclosures prompt accomodatory adjustments towards a more general change of 'feel' within workplaces, where relationships of generosity, reciprocity and care - for all - become normalised.

"[Although] it seems like an alien concept for many of my colleagues and superiors - more generosity and humility needed to others' angsts and problems" (Human geographer, mental health condition)

Second, most respondents called for greater attention to the well-being and mental health of all employees in academic workplaces. In particular, they called for greater appreciation of how academic workplaces may be exclusionary and anxiety-inducing for employees. In so doing, they recognised that the issues they had encountered - isolation, lack of support, distress, pressure, low self-esteem, fear of appearing 'weak' - overlapped with the often undisclosed experiences of many 'non-disabled' colleagues.

"More awareness and support networks, greater appreciation of how the academic lifestyle can be damaging or exclusionary for people who are not 100\% confident in themselves" (Human geographer, mental health condition)

"Review stress-causing practices and situations. Allow people to own up to their anxieties" (Physical geographer, mental health condition)

Third, echoing recent calls for more supportive Higher Education working environments (ECU 2008; LLUK 2009), respondents called for more consultative, collaborative and understanding relationships, generally, within academic workplaces. 
"Work together - collaboration between all staff, with a range of conditions, produces positive change which is beneficial to all" (Physical geographer, sensory impairment)

"Open discussion about issues. Less pressure/stress. More supportive working environment, where people are not made to feel like failures!" (Physical geographer, mental health condition)

In each of these senses, respondents called upon departments, institutions and disciplines to

challenge understandings of disabilities as individual problems to be 'solved' and instead challenge

longstanding norms of behaviour, interaction and career progression.

"A more friendly, supportive working environment - not everyone out to 'get' everyone else. My department is so competitive and self-centred and that colours the whole experience. There must be different ways of working..." (Human geographer, mental health condition)

\section{Acknowledgements}

**Details of funding; thank pre-submission readers

\section{References}

Allen C and Imrie R eds 2010 The Knowledge Business Ashgate, Aldershot.

Barnes C and Mercer G 2010 Exploring Disability Polity, Cambridge

Birnie J and Grant A 2001 Providing Learning Support for Students with Mental Health Difficulties Undertaking Fieldwork and Related Activities Geography Discipline Network, Cheltenham

Brunner R 2007 Exploring Disability Disclosure Amongst College and University Staff in Scotland Equality Forward, Stirling

Butler R and Bowlby S 1997 Bodies and spaces: an exploration of disabled people's experiences of public space Environment and Planning D: Society and Space 15 411-33

Chalkley B and Waterfield J 2001 Providing Learning Support for Students with Hidden Disabilities and Dyslexia Undertaking Fieldwork and Related Activities Geography Discipline Network, Cheltenham

Chouinard V 1996 'Like Alice through the looking glass': accommodation in academia Resources for Feminist Research 24 3-10

Chouinard V 1997 Making space for disabling differences: challenging ableist geographies Environment and Planning D: Society and Space 15 37987

Chouinard V 1999 Life at the margins: disabled women's explorations of ableist spaces. In Teather E (eds.) Embodied Geographies: spaces, bodies and rites of passage London, Routledge, pp.142-156

Chouinard V 2011 'Like Alice through the looking glass' II: the struggle for accommodation continues Resources for Feminist Research 33 161-178

Chouinard V and Grant A 1995 On not being anywhere near 'the project': ways of putting ourselves in the picture Antipode 27 137-166

Chouinard V, Hall E and Wilton R 2010 Introduction: towards enabling geographies in Chouinard V, Hall E and Wilton R eds Towards Enabling Geographies: 'Disabled' Bodies and Minds in Society and Space Ashgate, Aldershot 1-21

Conradson D 2003 Geographies of care: spaces, practices, experiences Social and Cultural Geography 4 451-54

Corker M 2000 The UK Disability Discrimination Act in France L and Silvers A eds Americans with Disabilities Routledge, London 357-77

Crooks V 2007 Exploring the altered everyday geographies and lifeworlds of women living with fibromyalgia syndrome Social Science and Medicine 64 577-588

Crooks V and Chouinard V 2006 An embodied geography of disablement: chronically ill women's struggles for enabling places in spaces of health care and daily life Health and Place 12 345-352

Crooks V, Chouinard V and Wilton R 2008 Understanding, embracing, rejecting: women's negotiations of disability constructions and categorisations after becoming chronically ill Social Science and Medicine 67 1837-1846

Curtis S 2010 Space, Place and Mental Health Ashgate, Aldershot

DRC [Disability Rights Commission] 2007 Disability Discrimination Act 1995: Code of Practice Post-16 DRC, London

DWP [Department for Work and Pensions] 2004 Disability in the Workplace DWP, London

Dyck I 1995 Hidden geographies: the changing lifeworlds of women with multiple sclerosis Social Science and Medicine 40 $307-320$

Dyck I 1999 Body troubles: women, the workplace and negotiations of disabled identity in Butler R and Parr H eds Mind and Body Spaces: Geographies of Illness, Impairment and Disability Routledge, London 119-37

ECU [Equality Challenge Unit] 2004 Employing Disabled People in Higher Education ECU, London

ECU 2008 Disclosure and Support Issues for Disabled Staff in Higher Education ECU, London

EHRC [Equality and Human Rights Commission] 2010 What Equality Law Means for You as an Education Provider - Further and Higher Education EHRC, Manchester

Gardiner V and Anwar N 2001 Providing Learning Support for Students with Mobility Impairments Undertaking Fieldwork and Related Activities Geography Discipline Network, Cheltenham

Hahn H 1986 Disability and the urban environment: a perspective on Los Angeles Environment and Planning D: Society and Space 4 273-88

Hall E 1999 Workspaces: refiguring the disability-employment debate in Butler R and Parr H eds Mind and Body Spaces: Geographies of Illness, Impairment and Disability Routledge, London 138-54

Hansen N and Philo C 2007 The normality of doing things differently: bodies, spaces and disability geography Tijdschrift voor Economische en Sociale Geografie 98 493-506

Harvey S, Henderson M, Lelliott P and Hotopft M 2009 Mental health and employment: much work still to be done British Journal of Psychiatry 194 201-3 
Healey M, Jenkins A, Leach J and Roberts C 2001 Issues in Providing Learning Support for Disabled Students Undertaking Fieldwork and Related Activities Geography Discipline Network, Cheltenham

HMSO [Her Majesty’s Stationery Office] 1995 Disability Discrimination Act 1995 HMSO, London

HMSO 2005 Disability Discrimination Act 2005 HMSO, London

HMSO 2010 Equality Act 2010 HMSO, London

Holt L 2007 Children's sociospatial (re)production of disability within primary school playgrounds Environment and Planning D: Society and Space $25783-802$

IDRM [International Disability Rights Monitor] 2004 International Disability Rights Center for International Rehabilitation, Chicago

Imrie R and Edwards C 2007 The geographies of disability: reflections on the development of a subdiscipline Geography Compass 1 623-40

Irvine A 2009 Something to Declare? The Disclosure of Common Mental Health Problems at Work. Social Policy Research Unit, York

LLUK [Lifelong Learning UK] 2009 Staff Disability Disclosure in the Lifelong Learning Sector LLUK, London

McDowell L 1997 Capital Culture: Gender at Work in the City Wiley, Chichester

McDowell L 1990 Sex and power in academia Area 22 323-332

Michalko R and Titchkosky T 2001Putting disability in its place: it's not a laughing matter in Wilson J and Lewiecki-Wilson C eds Embodied Rhetorics: Disability in Language and Culture Southern Illinois University Press, Carbondale 200-227

Moss P 1999 Autobiographical notes on chronic illness in Butler R and Parr H eds Mind and Body Spaces: Geographies of Illness, Impairment and Disability Routledge, London 155-66

Moss P, Debres K, Cravey A, Hyndman J, Hirschbroek K and Masucci M 1999 Toward mentoring as feminist praxis: strategies for ourselves and others Journal of Geography in Higher Education 23 413-427

Moss P and Dyck I 2002 Women, Body, Illness: Space and Identity in the Everyday Lives of Women with Chronic Illness Rowman and Littlefield, Oxford

NIACE [National Institute of Adult Continuing Education] 2008 From Compliance to Culture Change: Disabled Staff in Lifelong Learning NIACE, Leicester

Ní Laoire C and Shelton N 2003 'Contracted out': some implications of the casualisation of academic labour in geography Area 35 92-100

Park D, Radford J and Vickers M 1998 Disability studies in human geography Progress in Human Geography 22 208-33

Parr H 2003 Medical geography: care and caring Progress in Human Geography 27 212-21

Parr H 2008 Mental Health and Social Space. Oxford, Blackwell

Parr H and Butler R 1999 New geographies of illness, impairment and disability in Butler R and Parr H eds Mind and Body Spaces: Geographies of Illness, Impairment and Disability Routledge, London 1-24

QAA [Quality Assurance Agency for Higher Education] 2000 Code of Practice on Students with Disabilities QAA, Gloucester

QAA 2010 Code of Practice for the Assurance of Academic Quality and Standards in Higher Education. Section 3 - disabled students QAA, Gloucester

Price M 2011 Mad at School: Rhetorics of Mental Disability and Academic Life University of Michigan Press, Ann Arbor

RCPsych [Royal College of Psychiatrists] 2008 Mental Health and Work RCPSych, London

Rose G 1993 Feminism and Geography: the Limits of Geographical Knowledge Polity, Cambridge

Sainsbury R, Irvine A, Aston J, Wilson S, Williams C and Sinclair A 2008 Mental Health and Employment Department for Work and Pensions, London

Shepherd I 2001 Providing Learning Support for Blind and Visually Impaired Students Undertaking Fieldwork and Related Activities Geography Discipline Network, Cheltenham

Thomas R and Davies A 2002 Gender and new public management: reconstituting academic subjectivities Gender, Work and Organization $9372-$ 397

Titchkosky, T 2001 Coming out disabled: the politics of understanding Disability Studies Quarterly 21 131-139

Titchkosky, T 2007 Reading and Writing Disability Differently: the Textured Life of Embodiment University of Toronto Press, Toronto

Titchkosky T 2008 'To pee or not to pee?' Ordinary talk about extraordinary exclusions in a university environment Canadian Journal of Sociology $3337-60$

Vanhala L 2010 Making Rights a Reality? Disability Rights Activists and Legal Mobilisation Cambridge University Press, Cambridge

Wareham T, Clark G and Laugesen C 2001 Providing Learning Support for d/Deaf and Hearing Impaired Students Undertaking Fieldwork and Related Activities Geography Discipline Network, Cheltenham

Worth N 2008 The significance of the personal within disability geography Area 40 306-14

Worth N 2009 Understanding youth transition as 'becoming': identity, time and futurity Geoforum 40 1050-60 